

\title{
Study of Hot Tearing During Steel Solidification Through Ingot Punching Test and Its Numerical Simulation
}

Takao Koshikawa, Michel Bellet, Charles-André Gandin, Hideaki Yamamura, Manuel Bobadilla

\section{To cite this version:}

Takao Koshikawa, Michel Bellet, Charles-André Gandin, Hideaki Yamamura, Manuel Bobadilla. Study of Hot Tearing During Steel Solidification Through Ingot Punching Test and Its Numerical Simulation. Metallurgical and Materials Transactions A, 2016, 47 (8), pp.4053-4067. 10.1007/s11661016-3564-x . hal-01354150

HAL Id: hal-01354150

https://hal-mines-paristech.archives-ouvertes.fr/hal-01354150

Submitted on 3 Jan 2017

HAL is a multi-disciplinary open access archive for the deposit and dissemination of scientific research documents, whether they are published or not. The documents may come from teaching and research institutions in France or abroad, or from public or private research centers.
L'archive ouverte pluridisciplinaire HAL, est destinée au dépôt et à la diffusion de documents scientifiques de niveau recherche, publiés ou non, émanant des établissements d'enseignement et de recherche français ou étrangers, des laboratoires publics ou privés. 


\title{
Study of hot tearing during steel solidification through ingot punching test and its numerical simulation
}

\author{
Takao Koshikawa ${ }^{1,2}$, Michel Bellet ${ }^{1}$, Charles André Gandin ${ }^{1}$, \\ Hideaki Yamamura ${ }^{3}$, and Manuel Bobadilla ${ }^{4}$
}

\footnotetext{
${ }^{1}$ MINES ParisTech, CEMEF UMR CNRS 7635, 06904 Sophia Antipolis, France

${ }^{2}$ Nippon Steel \& Sumitomo Metal Corporation, Oita Works Equipment Division, 1 OazaNishinosu, Oita City 870-0992, Japan

${ }^{3}$ Formerly, Nippon Steel \& Sumitomo Metal Corporation, Steelmaking R\&D Division, 20-1 Shintomi, Futtsu City, Chiba Prefecture 293-8511, Japan, and now The Japan Institute of Metals and Materials, 1-14-32, Ichibancho, Aoba-ku, Sendai 980-8544, Japan

${ }^{4}$ ArcelorMittal Maizières, Research and Development, BP 30320, 57283 Maizières-lèsMetz, France
}

E-mail of the corresponding author: koshikawa.4eb.takao@jp.nssmc.com

\begin{abstract}
Experimental and numerical studies of hot tearing formation in steel are reported. On the one hand, an ingot punching test is presented. It consists in the application of a deformation at the surface of a solidifying $450 \mathrm{~kg}$ steel ingot. The experimental parameters are the displacement of the pressing tool, together with its velocity, leading to variations of a global strain rate. On the other hand, three-dimensional finite element thermomechanical modelling of the test is used. The time evolution of the strain tensor serves to compute an index to evaluate the susceptibility to create hot tears. It is based on the integration of a hot tearing criterion (HTC) that compares the local accumulation of strain with the expression of a critical value proposed in the literature. The main variable of the criterion is the brittleness temperature range (BTR) that refers to the solidification interval during which strain accumulates and creates hot cracks or tears. Detailed comparison of the simulation results with the measurements reveals the importance of the BTR for the prediction as well as excellent capabilities of the HTC to predict the formation of hot tears.
\end{abstract}




\section{Introduction}

The present paper focuses on a major defect encountered during secondary cooling in steel Continuous Casting (CC) known as hot tearing. Also named hot cracking or solidification cracking, this defect takes place deep in the mushy zone in regions close to the end of solidification, typically exceeding $90 \%$ of solid. A comprehensive description of the physical phenomena involved in hot tearing can be found in reference 1 . The liquid phase remaining at the late stage of solidification takes the form of thin interdendritic and intergranular films that cannot resist possible mechanical deformations. These are tensile stresses arising from external solicitations exerted by the immediate environment, for instance solidification shrinkage, thermal contraction of the neighboring regions, or boundary conditions restraining the product. Even low local deformations cannot be compensated by liquid feeding because of the extremely low permeability of the solid network at such high solid fractions. This leads to the rupture of the remaining liquid films, thus creating cracks. The material appears particularly vulnerable in a critical range of solid fraction, which is known as the Brittleness Temperature Range (BTR). Processing by $\mathrm{CC}$ leads to hot tearing formation during the bending or unbending of the strand, or as a consequence of bulging of the shell between support rolls under the effect of metallostatic pressure.

Locally and at small scale, various parameters influence the occurrence of hot tearing. The first of them is the chemical composition of the alloy. The larger the solidification interval is, the higher is its hot tearing sensitivity. Indeed, fragility strongly depends on the solidification path through the kinetic of liquid transformation near the end of solidification. In steels, some chemical elements such as sulfur, phosphorus or boron tend to increase the hot tearing sensitivity as they increase the solidification interval and thus decrease the solidus temperature [2]. Second, the microstructure also influences the hot tearing sensitivity. A fine microstructure decreases the sensitivity due to a better adaptation to the deformation: gliding at grain boundaries can accommodate small strains at low strain rates [3]. Accordingly, tearing resistance of an equiaxed structure is better than that of a columnar structure [4]. Note that the microstructure also determines the permeability and hence the compensation of strains by liquid feeding. Thirdly, wetting of the solid phase by the liquid phase depends on both temperature and liquid composition: a low wettability will promote the formation of solid bridges between grains which will help to resist tensions [5]. At last, the local thermomechanical behavior plays an important role in the appearance of hot tearing, itself being dependent on microstructure.

Recently, several researches focused on hot tearing phenomena. They can be divided into two groups; micro and macroscopic scale studies. The last decade has seen a significant development of numerical simulations directly operated at the scale of a Representative Elementary Volume (REV) of the mushy material, in view of encompassing most of the small-scale physical phenomena mentioned above. Phillion et al. [6] showed the influence of microstructual features on tensile deformation of a REV of semi-solid aluminum alloy. Sistaninia et al. [7] have developed a numerical simulation using a discrete element method in order to account for the strain inhomogeneity in the mushy zone due to crack initiation and propagation, in other words, direct simulation of hot tearing. Zaragoci et al. [8] considered a domain of few cubic millimeters deduced from in-situ X-ray tomography of a tensile test in an $\mathrm{Al}-\mathrm{Cu}$ sample maintained in the mushy state. A finite element discretization of the 3D domain using the level set method and adaptive mesh refinement was conducted to accurately separate liquid films and grains. The liquid flow and grain deformation were calculated, intrinsic properties of the phases obeying a viscoplastic constitutive equation. However, in those recent works [6-8], only fragments of the different physical phenomena taking part in hot tearing were accounted for. It can be thought that such small-scale models will develop in the future, integrating more and more relevant physical features, and thus will become useful 
tools for a better fundamental understanding of hot tearing. But upscaling of such models to deduce rules that can be applied at the processing scale, such as in continuous casting, will require time due to their computational cost and actual approximations of the physical phenomena. Therefore, it is necessary to focus on more macroscopic analysis methods to study hot tearing. Those constitute the second group of researches mentioned previously, if one is targeting process scale applications.

In the literature, lots of studies have proposed hot tearing criteria based on thermal considerations [9], solid mechanics [10-15] or solid and fluid mechanics [16]. Bellet et al. [15] have evaluated four of those hot tearing criteria for steels $[9,10,14,16]$ by means of constrained shrinkage tests and ingot bending tests. Systematic numerical simulation of the tests was conducted with the finite element package THERCAST ${ }^{\circledR}$ equipped with the different macroscopic criteria. The authors concluded that the only criterion able to show a qualitative agreement with the experimental tests was the strain-based criterion proposed by Won et al. [14]. They proposed an enriched expression to reach quantitative agreement [15]. In addition, Pierer et al. [3] evaluated, by use of submerged split chill tensile tests, a stress-based criterion [11], a strain-based criterion [14], a criterion based on strain rate and including liquid feeding consideration [16] and a criterion based on the sole BTR value [9]. The authors found that only the stress-based criterion and the strain-based criterion had good capability for predicting hot tearing. As a consequence, in the framework of the present study, we will essentially focus on hot tearing criteria based on critical strain.

Section 2 of this paper will consist of a review of macroscopic strain-based criteria and of their characterization through ingot bending or punching tests, as it will be shown that such tests are well suited to reproduce the context of continuous casting. Section 3 will present the ingot punching test developed in the framework of the present study. In Section 4, the thermomechanical finite element model will be presented including the effective implementation of the selected hot tearing criterion in the computation code THERCAST ${ }^{\circledR}$. Results of the numerical simulation of the punching tests and their comparison to experimental measurements will be presented and discussed in Section 5.

\section{A review of strain-based criteria and associated characterization through ingot bending or pressing tests}

As initially suggested by Yamanaka et al. [13], the basic expression to quantify the risk for the occurrence of hot tearing due to accumulation of strain is written as follows:

$$
F_{\mathrm{HT}}=\varepsilon_{\mathrm{BTR}}-\varepsilon_{\mathrm{c}}
$$

where $\varepsilon_{\mathrm{BTR}}$ is the local cumulated strain for a REV in the mushy zone during its cooling within a range of solid fraction. The second strain, $\varepsilon_{\mathrm{c}}$, is the critical strain at which cracks form. These quantities will be detailed and discussed hereafter. From Eq. (1), a positive value of the criterion function $F_{\mathrm{HT}}$ interprets as the onset of cracks as the cumulated strain locally exceeds the critical strain. Note that if one assumes a direct relationship between temperature and fraction of solid, the range of solid fraction transforms into a temperature interval called the brittleness temperature range (BTR).

For a given alloy, the critical strain value has to be established by experimental testing. The latter should be representative of the conditions of the solidification process for which the criterion is used. With this respect, the ingot bending or punching tests developed since the late 70's by steelmakers to estimate the CC-process viability are good candidates. Such tests have been developed by several authors [2, 17-21]. They consist in bending, punching, or 
pressing the solidifying shell of an ingot during its solidification by means of a punch moved perpendicularly to the shell plane (or surface of the ingot), i.e. along the dendritic growth direction when solidification proceeds directionally away from the mold walls. The size of the ingot and the control of the bending/punching conditions have to represent the solicitations undergone by the solid shell during CC when it passes through the support rolls. Note that in $\mathrm{CC}$, the alloy also endures the metallostatic pressure which induces bulging between each roll stand. Narita et al. [20] performed ingot punching tests on $72 \mathrm{~kg}$ steel ingots. This was done by moving a punch through an opening window designed in the mold. The displacement and the velocity of the punch were recorded during the tests, but the punching force was not measured. Another example is provided by Wintz et al. [2] who developed a three-point bending test performed on $300 \mathrm{~kg}$ steel ingots $\left(1200 \times 150 \times 250 \mathrm{~mm}^{3}\right)$ during their solidification in a thin $6 \mathrm{~mm}$-thick mold made of mild steel. The whole set -ingot plus moldwas bent by a cylindrical punch (maximum force $450 \mathrm{kN}$ ), the velocity of which was maintained constant in the range 0.1 to $5.5 \mathrm{~mm} \mathrm{~s}^{-1}$ during a short time. The surface temperature of the mold was measured by a pyrometer. The knowledge of the solidified thickness at the bending instant was obtained by a sulfur print made on a cross-section of a test-ingot in which the remaining liquid pool was on purpose and instantly enriched in sulfur at the instant of bending.

In this type of experiments, authors evaluated the applied deformation close to the solidification front by some simple bending formulae. The applied strain rate was directly deduced by dividing the total displacement imposed to the punch by the duration of its travel. It is worth noting that those estimations do not take into account neither the three-dimensional character of the test nor the fact that highly non uniform thermal gradients prevail through the shell thickness, inducing a gradient in the material strength. Therefore, the quantitative results deduced from these tests should be considered cautiously. However, from a qualitative point of view, results clearly demonstrate that the first order variable for crack occurrence is strain. Strain rate appears as a second order parameter, as the critical strain depends on strain rate (the higher the strain rate, the smaller the critical strain).

Nagata et al. [12] summarized lots of experimental results conducted on steels and draw the conclusion that the critical strain is related to the strain rate, $\dot{\varepsilon}$, by a power law. The slope of the log-form of this power law is a constant whatever the steel grade. The corresponding relationship thus is written as follows:

$$
\varepsilon_{\mathrm{c}}=A \dot{\varepsilon}^{-m^{*}}
$$

where $m^{*}$ is a constant while $A$ depends on steel grades (chemical composition). In addition, the authors introduced the concept of poor ductility zone in the direction of the ingot thickness, the extent of which is denoted $\eta$. Poor ductility is considered by the authors between the solidus temperature $T_{\mathrm{S}}$ and a lower temperature called "Zero Ductility Temperature" $T_{\mathrm{ZD}}$. This should not be seen as being contradictory to the definition of the BTR given above. Indeed, this may express the effect of intergranular coalescence. As demonstrated by Rappaz et al. [22] and illustrated by Wang et al. [23], stable liquid films could still cover grain boundaries to a lower temperature than the solidus temperature. Thus, in their paper, Nagata et al. proposed an expression of $T_{\mathrm{ZD}}$, or equivalently of the coalescence undercooling, as a function of the carbon, phosphorus and sulfur content [12]. Taking into account the non-linear temperature profile through the ingot shell (non-constant temperature gradient), the expression proposed for $\eta$ is

$$
\eta=d\left[1-\left(\frac{T_{\mathrm{ZD}}-T_{\text {surf }}}{T_{\mathrm{S}}-T_{\text {surf }}}\right)^{1.291}\right]
$$


where $d$ is the thickness of solidified shell and $T_{\text {surf }}$ is the surface temperature. It is worth noticing that $\eta$ can equivalently be expressed by the following formula:

$$
\eta=\frac{T_{\mathrm{S}}-T_{\mathrm{ZD}}}{\|\nabla T\|_{\eta}}
$$

which involves the local temperature gradient $\|\nabla T\|_{\eta}$ within the poor ductility zone. Nagata et al. noticed that the critical strain also obeys the following expression [12]:

$$
\varepsilon_{\mathrm{c}}=C \eta^{-n^{*}}
$$

where $C$ and $n^{*}$ are constants with positive values. Interpretation is that the smaller the poor ductility zone is, the larger is the critical strain required to form cracks (that is the smaller is the risk of hot tearing). Finally, in line with Eqs. (2) and (5), and on the basis of a compilation of several ingot bending experiments, the expression of the critical strain, as suggested by Nagata et al., is written as follows [12]:

$$
\varepsilon_{\mathrm{c}}=\frac{\phi}{\eta^{n^{*}}}\left(\frac{\dot{\varepsilon}}{3 \times 10^{-4}}\right)^{-m^{*}}
$$

where $m^{*}=0.167$ and parameters $\phi$ and $n^{*}$ are as follows:

$$
\left\{\begin{array}{l}
\text { If } 1 \mathrm{~mm}<\eta<3 \mathrm{~mm}, \text { then } \phi=0.0602 \text { and } n^{*}=2.13 \\
\text { If } 3 \mathrm{~mm}<\eta, \quad \text { then } \phi=0.0077 \text { and } n^{*}=0.258
\end{array}\right.
$$

Won et al. [14] proposed a similar expression. But rather than using the poor ductility extent $\eta$, which requires the knowledge of both the surface temperature $T_{\text {surf }}$ and the solidified shell thickness $d$, as in Eq. (3) and (6), they preferred to use directly the BTR value. The proposed expression for the critical strain is then

$$
\varepsilon_{\mathrm{c}}=\frac{\varphi}{\dot{\varepsilon}^{m^{*}} \Delta T_{\mathrm{BTR}}^{n^{*}}}
$$

where $\Delta T_{\mathrm{BTR}}$ is the extent of the BTR in Kelvin and $\varphi, m^{*}$, and $n^{*}$ are parameters. Through the analysis of many experimental data $[18,20,24,25]$, the authors identified constant values for those three parameters: $\varphi=0.02821, m^{*}=0.3131, n^{*}=0.8638$. They also mention that $\Delta T_{\mathrm{BTR}}$ should be calculated with a non-equilibrium microsegregation analysis, taking into account the steel composition and the cooling rate. Bellet et al. [15] conducted a similar discussion, showing the strong dependence of the effective value of the critical strain, $\varepsilon_{\mathrm{c}}$, with respect to the microsegregation model used for the determination of $\Delta T_{\mathrm{BTR}}$. Accordingly, and in line with Won et al. [14], they proposed a new expression for the critical strain, based on a BTR value calculated with a microsegregation model in equilibrium conditions, but with correction terms expressing the effective extent of the brittleness domain especially due to sulfur and phosphorus. This model was validated against the experimental results of Wintz et al. [2].

In the present study, a strain-based criterion - hereafter named WYSO from the initials of its authors - will be considered with the shape of Eq. (8), the BTR extent being calculated by means of different microsegregation models presented in the literature [28]. The latter point will be detailed and discussed in Section 5. 


\section{Ingot punching test}

The present punch press test has been designed and operated by Nippon Steel and Sumitomo Metal Corporation in the R\&D Centre of Futtsu, Japan. Steel grade for the present study is shown in Table 1. A schematic of the test is shown in Figure 1. It has been designed to mimic the thermomechanical solicitations taking place during CC processing of steel; for instance, with respect to the evolution of the cooling rate and deformation. The procedure of the experiments was as follows: the molten metal was prepared in an electric ladle furnace and the temperature was maintained at $1913 \mathrm{~K}\left(1640{ }^{\circ} \mathrm{C}\right)$, i.e. $129 \mathrm{~K}$ above the liquidus temperature. The molten metal was poured into the mold from the top through a tundish. The filling duration was about $70 \mathrm{~s}$ during which the temperature of the molten metal started decreasing due to heat exchanges with the tundish and with the mold. After filling, powder was added at the top of the ingot to limit heat exchanges with the air. The size of the ingot was $0.75 \mathrm{~m}$ height, $0.5 \mathrm{~m}$ width and $0.16 \mathrm{~m}$ thick. Its mass was approximately $450 \mathrm{~kg}$. In practice, a thermal insulator whose thickness was $5 \mathrm{~mm}$ covered the bottom part of the inner mold walls from the base of the ingot and up to $0.2 \mathrm{~m}$ height. This was required to avoid molten metal sticking and to make demolding easier. At a precise time after filling, the upper part of one of the two largest ingot surfaces (top right mold in Figure 1) was moved upward. The lateral surface of the ingot was then in direct contact with the air. Note in Figure 1 that this side of the mold is made of two parts positioned one on top of the other. The bottom part could thus be kept at the same place when the top part was removed. A punching tool was then put into contact with the lateral vertical free surface of the ingot. It consists of a horizontal $0.12 \mathrm{~m}$-diameter $0.3 \mathrm{~m}$ - long cylinder with length centered on the main vertical face of the ingot, its longitudinal axis aligned with the $\mathrm{Z}$ direction at height $0.45 \mathrm{~m}$ from the bottom of the ingot. The tool velocity and displacement are controlled by means of a hydraulic system and recorded during the test. The reaction force is also measured using the time evolution of the hydraulic system pressure. The test conditions referred to as N-2 to N-6 are summarized in Table 1, together with measured nominal compositions in the ladle before filling. Note that a unique alloy composition was targeted for the experimental results reported hereafter. To know temperature evolution during the test, type-B thermocouples labelled TC-1 and TC-2 in Figure 1 were positioned in the ingot. For that purpose, two horizontal holes were created in the fixed large face of the mold (at left in Figure 1). Thermocouples were inserted into these holes from outside. They were positioned in the mold cavity at desired location. The holes diameter was $5.5 \mathrm{~mm}$. For sealing purpose, thermal insulator was put into the holes after setting thermocouples. In addition, type-K thermocouples were placed in the fixed large face of the mold in trial N-4. The ingot surface temperature was also measured with a pyrometer, labelled PM in Figure 1, in trial N-4 before and after deformation when the top right mold was removed.

After completion of casting and cooling to room temperature, the ingot was cut and appropriate etching was conducted to investigate hot tearing occurrence considering its intensity and locations in micrographs. The cut was performed in the section $\mathrm{Z}=0 \mathrm{~m}$ schematized in Figure 1(b), i.e. a transverse section that reveals the entire ingot thickness and height and is located at mid-width. Figure 2(a) shows a typical section for trial N-4. The punching tool comes from the right-hand side in the figure. In front of the punching tool, a columnar dendritic microstructure grew from the ingot surface toward the ingot center. The columnar dendrites are slightly oriented upward as is shown in Figure 2(b). This could be due to a downward liquid flow in the melt in front of the growing dendrites, as expected from previous analyses [29]. Around the center of the ingot, the morphology is changed to equiaxed due to the decrease of the temperature gradient in the liquid ahead of the growing front [30]. At the top, primary shrinkage is observed with a large void located slightly below the top solid shell. In order to avoid thermal exchange at the top, a thermal insulator powder was put on the free liquid/air interface just after filling. However, thermal exchange was not 
completely stopped and a thin solid shell formed. Upon further cooling, shrinkage flow leads to a typical ingot top-surface depression shape and a large void underneath. Considering the bottom of the ingot, the morphology is almost equiaxed and voids are also found. These observations are attributed to shrinkage upon solidification of an isolated hot liquid pocket. In fact, solidification is delayed in the bottom part of the ingot compared to the area located in front the punching tool because of the thermal insulator material deposited at the bottom surface of the mold to avoid metal sticking. The temperature gradient is also lowered at the bottom part, facilitating the formation of an equiaxed zone and large shrinkage porosity. Yet, void formation is not studied hereafter, as the main interest for this study is hot tearing in the section of the ingot located in front of the punching tool. Detailed analysis reveals the formation of the hot tears, as shown in Figure 2(b). The cracks are aligned with the columnar dendrites, as expected from previous observations in the literature [31]. In this micrograph, it seems stopped by the equiaxed zone. Its length reaches $20 \mathrm{~mm}$ in the cross section, although hot tears are obviously three-dimensional objects and this value should be seen as an underestimation. Also worth noticing is the absence of hot tear on the side of the ingot opposite to the punching tool (e.g. in region $\mathrm{X}>0$ according to Figure 1). The total number and length of cracks observed in the transverse metallographic cross sections were measured to estimate the intensity of hot tearing as a function of the experimental conditions.

\section{Thermomechanical finite element modeling}

\subsection{Finite element modeling with THERCAST ${ }^{\circledR}$}

The numerical simulation of the punching tests consists of a thermomechanical stress/strain analysis. It is conducted using the 3D finite element code THERCAST ${ }^{\circledR}$. The essential characteristics of the code can be found in References 32 and 33. Non-linear average conservation equations for the total mass, momentum and energy are solved at each time increment on all interacting domains shown in Figure 1: the ingot, the different components of the mold, and the pressing punch. Yet, as regards the mechanical problem, only the ingot is considered as deformable; the mold components and the punch are assumed rigid. In the ingot, the solution covers the whole domain occupied by the metal, whatever its state: liquid, solid, or mushy. The semi-solid steel (composed of liquid and solid phases) is simply considered as a homogenized continuum with averaged properties and a unique average velocity field $\mathbf{v}$. The thermal problem and the mechanical problem are solved sequentially at each time increment. First, the average energy conservation is solved in all domains taking into account heat exchange between them. This equation can be expressed by

$$
\rho \frac{d h}{d t}=\nabla \cdot(\lambda \nabla T)
$$

where $\rho$ is the average density, $h$ is the average specific enthalpy per unit mass, $\lambda$ is the average thermal conductivity and $T$ is the temperature. Second, the mechanical problem is considered. The following average momentum and mass conservation equations are solved concurrently in the framework of a velocity-pressure formulation.

$$
\left\{\begin{array}{l}
\nabla \cdot \mathbf{s}-\nabla p+\rho \mathbf{g}-\rho \mathbf{\gamma}=0 \\
\operatorname{tr} \dot{\boldsymbol{\varepsilon}}^{\mathrm{vp}}=0
\end{array}\right.
$$

where $\mathbf{s}$ is the deviatoric stress tensor, $p$ is the pressure, $\mathbf{g}$ is the gravity vector, $\gamma$ is the acceleration vector and $\dot{\boldsymbol{\varepsilon}}^{\mathrm{vp}}$ is the viscoplastic part of the strain rate tensor $\dot{\boldsymbol{\varepsilon}}=\left(\nabla \mathbf{v}+\nabla^{\mathrm{T}} \mathbf{v}\right) / 2$.

The alloy is modeled with a hybrid constitutive equation. Details can be found elsewhere [34], only main lines being recalled here. Over the solidus temperature, the alloy is considered as a 
non-Newtonian fluid obeying a temperature-dependent viscoplastic multiplicative law, as follows:

$$
\bar{\sigma}=K(\sqrt{3})^{m+1} \dot{\bar{\varepsilon}}^{m}
$$

where $\bar{\sigma}$ is the equivalent von Mises stress, $K$ is the viscoplastic consistency, $\dot{\bar{\varepsilon}}$ is the generalized strain rate and $m$ is the strain rate sensitivity. The value of $m$ over the liquidus temperature is equal to 1 (Newtonian fluid). In the frame of the present study, liquid flow in liquid regions is ignored and the liquid viscosity is defined as $10 \mathrm{~Pa}$ s for numerical stability reasons. Below the solidus temperature, the alloy obeys an elastic-viscoplastic constitutive equation, expressed by:

$$
\bar{\sigma}=K(\sqrt{3})^{m+1} \dot{\bar{\varepsilon}}^{m}+H \bar{\varepsilon}^{n}
$$

in which $\bar{\varepsilon}$ is the cumulated plastic strain, $H$ is the strain hardening coefficient and $n$ is the strain sensitivity. Physical properties and constitutive parameters are temperature dependent.

\subsection{Implementation of the hot tearing criterion}

In this study, the WYSO hot tearing criterion proposed by Won et al. [14] is evaluated. Being interpreted like in [15], this criterion is based on the cumulated strain in the plane perpendicular to the dendritic growth direction, this direction being assumed as the temperature gradient direction. The corresponding strain rate is denoted $\dot{\hat{\varepsilon}}$. Following Eqs. (1) and (8), the strain-based criterion $F_{\mathrm{HT}}^{\text {WYSO }}$ is expressed as follows:

$$
F_{\mathrm{HT}}^{\mathrm{WYSO}}=\int_{B T R} \dot{\hat{\varepsilon}} \mathrm{d} t-\hat{\varepsilon}_{\mathrm{c}} \quad \text { with } \quad \hat{\varepsilon}_{\mathrm{c}}=\frac{\varphi}{\hat{\hat{\varepsilon}}^{m^{*}} \Delta T_{\mathrm{BTR}} n^{*}}
$$

where $\hat{\varepsilon}_{\mathrm{c}}$ denotes the strain limit which depends itself on the strain rate perpendicular to the thermal gradient and on the BTR extent. The value of parameters $\varphi, m^{*}$, and $n^{*}$ have already been reported in Section 2 [14]. The values of the characteristic solid fractions bounding the BTR will be discussed further. As regards $\dot{\hat{\varepsilon}}$, it is calculated as follows. The strain rate tensor $\dot{\boldsymbol{\varepsilon}}$ is first calculated in a reference frame attached to the temperature gradient direction, the two complementary directions defining the perpendicular plane. From the four components of the tensor $\dot{\boldsymbol{\varepsilon}}$ in this plane, it is possible to calculate two eigen values. Considering that hot tearing takes place under tension, $\dot{\hat{\varepsilon}}$ is defined as the largest positive eigen value.

In THERCAST ${ }^{\circledR}$, given the linear interpolation of the velocity field in tetrahedral elements, the velocity gradient is uniform in each element, and so is the value of $\dot{\hat{\varepsilon}}$. Hence, the criterion $F_{\mathrm{HT}}^{\mathrm{WYSO}}$ has been implemented as a constant field in each finite element, e. It is seen from Eq. (13) that the definition of the strain rate used to define the critical strain $\hat{\varepsilon}_{c}$ can give rise to interpretations and discussions. The selected implementation procedure is detailed here. At each time increment $i$, the following quantity is calculated:

$$
F_{\mathrm{HT}, \mathrm{e}}^{\mathrm{WYSO}, \mathrm{i}}=\sum_{\mathrm{j}=\mathrm{i} \_ \text {start }}^{\mathrm{i}} \dot{\hat{\varepsilon}}_{\mathrm{e}}^{\mathrm{j}} \Delta t^{\mathrm{j}}-\frac{\varphi}{\left(\dot{\hat{\varepsilon}}_{\mathrm{e}}\right)^{m *} \Delta T_{\mathrm{BTR}} n^{*}}
$$

where i start is the time increment at which element e enters the BTR, and $\Delta t^{\mathrm{j}}$ is the time step at time increment $\mathrm{j}$. The time increment at which element e exits the BTR is denoted 
i_end. During the crossing of the BTR, the maximum value of the quantities $F_{\mathrm{HT}, \mathrm{e}}^{\mathrm{WYO}, \mathrm{i}}$ is retained to form the hot tearing criterion. Finally, in each element e the criterion value is defined as:

$$
F_{\mathrm{HT}, \mathrm{e}}^{\mathrm{WYSO}}=\underset{\text { i=i_starti_end }}{\operatorname{Max}}\left(F_{\mathrm{HT}, \mathrm{e}}^{\mathrm{WYSO}, \mathrm{i}}\right)
$$

\subsection{Simulation of ingot punching tests}

As illustrated in Figure 1, half of the setup is simulated, because of the symmetry with respect to the central transverse vertical section plane. The simulation encompasses 7 domains: the ingot, 5 mold components, and the punching tool. In the ingot, the initial mesh size is $8 \mathrm{~mm}$ and the number of elements is approximately 600,000. For better accuracy in the deformed region, remeshing is performed to decrease the mesh size to $4 \mathrm{~mm}$ just before punching, leading to $1,000,000$ elements. The filling stage is not taken into account so that the thermomechanical simulation starts at the end of the filling stage ( $70 \mathrm{~s}$ after filling start). The corresponding "initial" temperature of the ingot at that time, $1823 \mathrm{~K}$, is estimated thanks to the measurements. It is set to $293 \mathrm{~K}$ for all other domains. The thermal boundary condition in between ingot and mold is defined through a heat transfer coefficient, the value of which depends on the air gap which may form at the interface because of shrinkage and thermal contraction. When the ingot is into contact with the mold, the heat transfer coefficient is calibrated by comparison with measurements. Its value is set to $850 \mathrm{~W} \mathrm{~m}^{-2} \mathrm{~K}^{-1}$. When air gap forms, its width is considered and a heat transfer coefficient is computed taking into account radiation and heat conduction through the air gap [34]. Regarding the ingot top, an adiabatic condition is used, thus modeling the use of the powder thermal insulator. After partial mold removal, a free surface heat exchange condition is applied to this region of the ingot surface by accounting for radiation and convection with the air at $293 \mathrm{~K}$, with the values for emissivity and convective heat transfer coefficient taken as 0.8 and $15 \mathrm{~W} \mathrm{~m}^{-2} \mathrm{~K}^{-1}$, respectively.

Three different solidification paths are given in Figure 3. The first one is based on the lever rule (LR) approximation, meaning that full thermodynamic equilibrium is assumed in all existing phases at any temperature. The second one is a combination of the partial-equilibrium (PE) approximation together with the para-equilibrium approximation (PA). It accounts for the fact that $\mathrm{C}$ is an interstitial element with large diffusivity compared to substitutional elements that are frozen in the solid phases. In addition, the PE+PA approximation accounts for the peritectic reaction taking place in the steel grade investigated in this study. The details of these approximations and the solidification paths for similar alloy compositions are given elsewhere [28, 35]. The last solidification path (EX) is extracted from measurements conducted on a sample using interrupted unidirectional solidification. Finally, the BTR chosen in the present study is limited by solid fractions 0.9 and 0.99 . Calculated values are listed in Table 2 for the three solidification paths given in Figure 3.

Graphs in Figure 4(a) and (b) show a comparison of experimental stress-strain plots with calculated curves based on Eq. (13). The comparison indicates a good agreement. The temperature dependence of the corresponding constitutive coefficients in Eqs. (12-13) is given in Figure 4(c). Thermophysical properties shown in Figure 5(a) are deduced from the TCFE6 database assuming full equilibrium solidification path [38, 39]. Latent heat is estimated to $260000 \mathrm{~J} \mathrm{~kg}^{-1}$. Tabulation of the thermal conductivity as taken from [36] is also given in Figure 5(b). 


\section{Results and discussion}

Results for experiment N-4 are first considered, a global view of the structure observed in a transverse metallographic cross section being provided in Figure 2. Analyses of the temperature history and punch force evolution permit to introduce measurements and their comparison with numerical simulations. This is done considering the 3 solidification paths shown in Figure 3, corresponding to the BTR values reported in Table 2, as parameters for the simulations. The set of data detailed for N-4 are then compared with those for N-5 and N-6. As can be deduced from Table 1, the punching time is doubled in N-5 as the total displacement of the punching tool is the same as for $\mathrm{N}-4$ while the velocity of the punching tool is twice smaller. For trial N-6, the punching time is the same as for N-4 since the total displacement has been reduced by a factor 2 with the same velocity as for N-5. Finally, results for all trials are reported in the same graphs for a global analysis and discussion.

\subsection{Thermomechanical validation}

Figure 6 shows the cooling curves recorded in the N-4 trial ingot by thermocouples TC- 1 and TC-2. TC-1 (blue curves in Figure 6) is located at the center of the ingot thickness and at $190 \mathrm{~mm}$ from the narrow face (or inner wall of the side mold). Comparatively, TC-2 (red curves in Figure 6) is closer to the narrow face ( $90 \mathrm{~mm}$ from the side mold) but still close to mid-thickness (only $20 \mathrm{~mm}$ off). Both thermocouples are at the same height, i.e. only $20 \mathrm{~mm}$ below the impact position of the punching tool with the ingot surface. Surface temperatures at the height of the punching tool using the pyrometer are also reported (circle marks in Figure 6). The calculated temperature evolution at the location of the thermocouples is in good agreement with measured data from about $300 \mathrm{~s}$. Before this time, simulated cooling curves reveal an overestimation of the temperatures compared to measurements. A series of additional simulations were performed by progressively decreasing the liquid viscosity during the first $300 \mathrm{~s}$. With more realistic properties of the melt, the predicted temperature came closer to the measurements. It should also be pointed out that the filling stage of the mold by the molten metal was not modeled. It is expected that it would further homogenize the temperature. Temperature evolution during the punching test is yet well predicted.

After $300 \mathrm{~s}$, the top-right mold located in front of the punching tool is removed (Table 1). Simulation shows that the surface temperature of the ingot then increases (green curve in Figure 6). This is expected as the heat flux decreases in the absence of the mold. At $484 \mathrm{~s}$, identified by a dashed vertical orange line, the punching tool is in contact with the ingot surface. Pressing starts $15 \mathrm{~s}$ later, at $499 \mathrm{~s}$, and lasts for $12 \mathrm{~s}$ (Table 1). The start/end of the pressing sequence is identified by the 2 vertical orange lines in Figure 6. While no thermal signature of the punching test is made visible with the thermocouples located in the core of the ingot, it can be seen on the simulated curve extracted at the ingot surface in front of the punching tool. A large temperature decrease precedes the punching sequence, with a minimum temperature reached immediately after punching. While the punching tool goes backward with a velocity of $1.0 \mathrm{~mm} / \mathrm{s}$ after punching, the temperature increases up to approximately the same level as before punching. Although it cannot be measured during pressing, the calculated temperature evolution is in good agreement with the pyrometer measurement (green symbols in Figure 6).

In order to further validate the thermomechanical simulations, the time evolution of the reaction force acting against the imposed displacement of the punching tool is plotted in Figure 7(a) for trial N-4. It is to be compared with the recorded force on the punching tool. Globally, the agreement of the simulation with measurement is good. When comparing the predictions obtained with the different solidification paths, it can be seen that an excellent agreement with the measurement is reached for the simulation using the PE+PA approximation. No large variation can be found when using EX or LR. However, the fact that 
the prediction using LR leads to a larger reaction force reveals the presence of a stiffer solid shell when pressing is applied. Indeed, according to LR, a higher quantity of solid is indeed present as expected from Figure 3 when considering a given temperature distribution.

Overall, the comparison of temperature and force evolutions demonstrates that thermomechanical evolutions are well simulated from about $300 \mathrm{~s}$ and up to the completion of solidification, thus demonstrating the use of satisfying thermophysical and rheological properties, as well as boundary conditions. Similar observations could be done for the other trials as shown for N-5 and N-6 in Figure 7(b) and (c). These results confirm that quantitative agreement is found for the thermomechanical load applying on the ingot surface. This provides a sound basis in the use of the model for further interpretation of the distribution of stresses and strains, as well as their exploitation to evaluate the selected hot tearing criterion.

\subsection{Stress distribution and hot tearing criterion}

Figure 8 shows the numerical simulation results just after punching for trial N-4 with the solidification path labeled PE+PA in Figure 3 and Table 2. The various parts of the mold and the punching tool appear with a uniform grey color, while the ingot section and surface are colored according to the distribution of (a) the temperature, (b) the first principal stress component $\sigma_{\mathrm{I}}$, and (c) the hot tearing criterion $F_{\mathrm{HT}}^{\mathrm{WYSO}}$. As this is a magnified view through the various domains of the simulation shown in Figure 1, only the left, bottom-right and side parts of the mold are partially made visible. The top-right part of the mold has already been removed and the bottom part is invisible in this field of view. The cylindrical punching tool is also visible. From this view, one can better see the analogy made with the interaction with rolls in the secondary cooling zones of continuous casting machines. At the end of punching, for trial N-4, it can first be seen that a region of fully molten liquid steel still exists at the center of the ingot where the temperature is higher than the liquidus temperature of the alloy, $1784 \mathrm{~K}$, while the surface temperature remains over $1273 \mathrm{~K}$. Isotherms also reveal that the average temperature of the right-hand-side domain of the ingot is hotter than the left-hand-side. This is compatible with the previous description of the predicted cooling curves shown in Figure 6 as cooling was found to be delayed in the absence of the top-right mold.

Figure 8(b) presents the field of the first principal stress component, just before and just after punching. For a better representation, only the tensile state is colored, regions in compression (with negative value of this first principal stress component) being represented with the same grey color as the mold parts and tool. First, it can be seen that a small region below the ingot surface, in front of the tool, is compressed. Second, and as expected from the bending created by the punch movement, tensile stresses generate and their values increase when going deeper into the ingot. However, the maximum value (around $6 \mathrm{MPa}$ ) is not found in the mushy zone, but in the solid, just beside the mushy zone. This is because the stiffness of the material is continuously decreasing with increasing temperature, with an abrupt decay at the solid/mushy transition. Tensile stresses also form on the left-hand-side but with a much lower intensity than on the punch side.

The distribution of the values of the hot tearing criterion $F_{\mathrm{HT}}^{\mathrm{WYSO}}$ is displayed in Figure $8(\mathrm{c})$. It is reminded here that those values result from an incremental build-up when crossing the BTR, as expressed by Eqs. (14) and (15). Like for the tensile stress, only representations of regions with positive value are shown, corresponding to higher risk to form tear defects. Before punching and outside of the punching zone, there is no trace of hot tearing risk. The negative values of the criterion express that the "natural" solidification of the ingot is globally 
sound. Conversely, after bending, positive values appear, the higher ones being found on the punching side, at the height of the punching tool, close to the end of solidification, within the BTR. This is clear in Figure 8(c): after punching the maximum values are within the contours defined for the fractions of solid 0.9 and 1. At the end of a casting simulation, when the ingot is fully solid, the final $F_{\mathrm{HT}}^{\text {WYSO }}$ map is made by retaining those values and reveals a high hot tearing sensitivity only in the ingot region facing the punching tool.

\subsection{Hot tearing prediction versus observations}

Figure 9 shows a magnified view of the micrograph for trial N-4. It is extracted from the cut schematized in Figure 1(b) and shown in Figure 2(a). In fact, the top hot tear circled in Figure 9 is the same as the one shown in Figure 2(b). Cracks were only found on the punching side of the ingot. Their number and position were measured. This was done by counting the number of cracks along the height of the ingot as a function of the distance from the punching side, i.e. the right-hand-side limit of the images. Results are also presented in Figure 9 for trial $\mathrm{N}-4$. The black stepwise line is thus a direct reading of the intensity of defects found. In fact, the range over which cracks are present depends on the crack lengths and the crack density is directly proportional to the number of cracks. A total of maximum 3 tears were counted $50 \mathrm{~mm}$ away from the ingot surface where pressing was applied. Cracks are present between 40 to $60 \mathrm{~mm}$. Note that this range is close to the length of the circled crack in Figure 2(b), thus the longest in this sample.

Profiles are also provided for the criterion $F_{\mathrm{HT}}^{\mathrm{WYSO}}$ in Figure 9. Positive values normally correspond to the occurrence of cracks. Considering the PE+PA solidification path (red curve), cracks are predicted to occur over a distance ranging from 36 to $50 \mathrm{~mm}$. This is not far from the prediction using the experimental solidification path (EX, green curve). However, it also becomes clear from Figure 9 that prediction using the LR approximation (blue curve) is not satisfying as it almost never leads to positive values for $F_{\mathrm{HT}}^{\mathrm{WYSO}}$. The reason is linked to the small extent of the BTR (Table 2) in the case of LR. Cumulated strain computed within this small temperature interval does not permit to reach the critical strain thus positive values of $F_{\mathrm{HT}}^{\mathrm{WYSO}}$ over a satisfying distance. This also corroborates the finding described for the simulated reaction force that LR does not lead to results as good as the PE+PA approximation. However, while differences between PE+PA and LR when predicting the reaction force were not large, the effect on $F_{\mathrm{HT}}^{\mathrm{WYSO}}$ becomes spectacular. The effect of the solidification path is thus evidenced, revealing the crucial role of the microsegregation model for the prediction of hot tearing.

\subsection{Comparison of experiments and discussions}

Figure 7 and Figure 9 also present results of analyses for trials N-5 and N-6. Similar observations can be given for the reaction force prediction and its comparison with measurements through Figure 7. In Figure 9, however, a large number of cracks is visible for trial N-5 while very few and short ones are found for trial N-6. Again, a more quantitative illustration is given in the bottom line of Figure 9. This observation is retrieved in the distribution with a maximum number of cracks count reaching 10 at around $50 \mathrm{~mm}$ reported in Figure 9 for trial N-5, while only a maximum of 2 cracks are reported in Figure 9 for trial N-6. Similar trends are predicted with the distribution of the $F_{\mathrm{HT}}^{\mathrm{WYSO}}$ value along the profile. The maximum $F_{\mathrm{HT}}^{\mathrm{WYSO}}$ value is reached for trial N-5 while it only slightly overpasses the zero-limit from which defects are expected to form for trial N-6. In Figure 9 trial N-5 
corresponds to twice the time for the reaction time and a lower reaction force for trial N-6 since the total displacement has been reduced by a factor 2 compared to trial $\mathrm{N}-4$. Such results confirm the pertinence of the selected hot tearing criterion. Similar analyses as for N-4 again reveal the critical role played by the solidification path to determine the BTR extent.

In an effort to analyze the cumulated strain criterion and to compare results with literature, Figure 10 presents limit curves predicted by the WYSO criterion when based on the three solidification paths. The continuous curves correspond to the strain limit $\hat{\varepsilon}_{\mathrm{c}}(\dot{\bar{\varepsilon}})$ that constitutes the second term of the WYSO criterion in Eq. (13). Note that in the expression of $\hat{\varepsilon}_{\mathrm{c}}(\dot{\widehat{\varepsilon}})$, the BTR extent is known a priori from the solidification path (Table 2). Thus, for each curve, the half space located above the curve corresponds to $F_{\mathrm{HT}}^{\mathrm{WYSO}}>0$, expressing a higher risk to form hot tearing defects. According to its smaller BTR extent, the LR limit curve is shifted toward the top-right region of the graph while the PE+PA limit curve is located in a lower (left-bottom) region, the EX limit falling in between. Calculated values are superimposed on the figure for trials N-2 to N-6. To this end, for each test, the profile of $F_{\mathrm{HT}}^{\mathrm{WYSO}}$ along the thickness of the ingot at the punching tool height is exploited. The maximum value for $F_{\mathrm{HT}}^{\mathrm{WYSO}}$ is taken from the profile as well as the corresponding value at the same position for the perpendicular cumulated strain: $\int_{B T R} \dot{\hat{\varepsilon}} \mathrm{d} t$. The corresponding perpendicular strain rate is then recomputed with Eq. (13), using the obtained values for the maximum $F_{\mathrm{HT}}^{\mathrm{WYSO}}$ and the cumulated strain. The distribution of the results in the graph is linked to the applied displacement and velocity of the punching tool as shown in Table 1. It is found that the microsegregation model does not play a major role on the perpendicular cumulated strain and the perpendicular strain rate in the BTR since the three points for each trial are very close. Note that, while metallographic investigations of all these trials have revealed the presence of hot tears, only the PE+PA and EX curves give a good response. The simulation using LR does not work as N-6 is not located in the crack risk region and was yet shown to present defects.

Considering the results presented above, it appears that the expression of $F_{\mathrm{HT}}^{\mathrm{WYSO}}$ not only provides us with a criterion to predict the formation of hot tears but also has potential to predict their magnitude. In order to reveal this behavior, a hot tearing index is built by considering a simple addition of the crack length measured in each of the experiments. Figure 11 presents the value of cumulated hot tearing length, expressed in millimeters, as a function of the maximum value for $F_{\mathrm{HT}}^{\mathrm{WYSO}}$ obtained from its profile at punching height based on the $\mathrm{PE}+\mathrm{PA}$ solidification path for each experiment. A positive slope is found, that shows a significant correlation between the calculated value of the criterion function and the effective crack intensity as deduced from cumulated measured crack lengths. This indicates that the strain based criterion can also be used to predict the hot tearing magnitude.

\section{Conclusions}

A hot tearing study has been performed during steel solidification. Analyses include

- punching tests using a tool to press the semi-solid ingot while it is solidifying, thus mimicking deformation under the rolls of a continuous casting machine,

- several trials conducted for various values of the total deformation and velocity of the pressing tool, 
- measurements including thermal history through the use of thermocouples and a pyrometer as well as the reaction force acting against the imposed displacement of the pressing tool,

- thermomechanical simulations of each trials using finite element simulations,

- metallographic investigation of a transverse cross section of the ingot and systematic count of all cracks found to evaluate the intensity of defect formation,

- integration of a cumulated strain based hot tearing criterion (HTC),

- comparison of predictions with observations.

Main findings are as follows:

- the HTC is able to predict the risk of crack formation, provided that the brittleness temperature range (BTR) is adequately reproduced,

- predictions in a cumulated strain versus strain rate perpendicular to the temperature gradient, as well as the reaction force, does not evidence large variation with the BTR, nor did the thermal history,

- the role of the BTR is evidenced when drawing the HTC profile along the ingot thickness, thus revealing the critical effect of the selected solidification path,

- excellent correlation is found between measurements and simulations concerning the position and intensity of the hot tears.

As a perspective to the present work, considering the strong sensitivity of the hot tearing prediction to the solidification path, coupling with macrosegregation has to be modeled. Indeed, deformation induced composition variations are expected to generate variations in solidification paths [37]. This is particularly true when considering alloying elements such as $\mathrm{C}, \mathrm{S}$ or $\mathrm{P}$ for which low concentration variations can generate large deviations of the solidus temperature. The numerical modelling of this coupling with macrosegregation requires in turn the calculation in the mushy zone of the concurrent deformation of the solid phase and liquid flow. Some work has been initiated by the authors of the present paper [41-43] by use of a two-dimensional "two-phase" thermomechanical model [42, 43]. However, a general 3D framework implementing concurrently macrosegregation and hot tearing is still missing in the literature. Further developments in this direction are foreseen.

\section{Acknowledgments}

This work is supported by Nippon Steel \& Sumitomo Metal Corporation (NSSMC) in a collaborative project with ArcelorMittal (AM). The authors are deeply grateful to Dr Olivier Jaouen and Dr Frédéric Costes from TRANSVALOR (Mougins, France), for their kind help and discussion about thermomechanical modeling using software THERCAST ${ }^{\circledR}$. 


\section{References}

1. J. Campbell: Castings, Butterworth-Heinemann, Oxford, United Kingdom, 1991

2. M. Wintz, M. Bobadilla, and M. Jolivet: La Revue de Métallurgie, 1994, vol. 4, pp. 105 114

3. R. Pierer, C. Bernhard, and C. Chimani: La Revue de Métallurgie, 2007, vol. 2, pp. 72-83

4. D.G. Eskin, Suyitno and L. Katgerman: Progress in Materials Science, 2004, vol. 49, pp. 629-711

5. M. Braccini: Doctotal Thesis, 2000, Institut National Polytechnique de Grenoble

6. A.B. Phillion, S.L. Cockcroft, and P.D. Lee: Acta Mater., 2008, vol. 56, pp. 4328-4338

7. M. Sistaninia, A.B. Phillion, J.M. Drezet, and M. Rappaz: Metall. Mater. Trans. A, 2011, vol. 42, pp. 239-248

8. J.F. Zaragoci, L. Silva, M. Bellet, and C.A. Gandin: Proc. MCWASP XIII, 13th Int. Conf. on Modelling of Casting, Welding and Advanced Solidification Processes, Schladming (Austria), June 17-22, 2012, A. Ludwig, M. Wu, A. Kharicha (eds.), IOP Conference Series 33 (2012) 012054, 8 pages

9. T.W. Clyne and G.J. Davies: Solidification and Casting of Metals, TMS, Warrendale, PA, 1977, pp. 275-278

10. N.N. Prokhorov: Russian Castings Production, 1962, vol. 2, pp. 172-175

11. B. Rogberg: Scand. J. Metall., 1983, vol. 12, pp. 51-66

12. S. Nagata, T. Matsumiya, K. Ozawa, and T. Ohashi: ISIJ Int, 1990, vol. 76 (2), pp. 214 221

13. A. Yamanaka, K. Nakajima, K. Yasumoto, H. Kawashima, and K. Nakai: Proc. $5^{\text {th }}$ Int. Conf. on Modeling of Casting, Welding and Advanced Solidification Processes, 1991, M.

Rappaz, M.R. Ozgu, and K.W. Mahin (eds.), TMS, pp. 279-284

14. Y.M. Won, T.J. Yeo, D.J. Seol, and K.H. Oh: Metall. Mater. Trans. B, 2000, vol. 31, pp. 779-794

15. M. Bellet, O. Cerri, M. Bobadilla, and Y. Chastel: Metall. Mater. Trans. A, 2009, vol. 40, pp. $2705-2717$

16. M. Rappaz, J.M. Drezet, and M. Gremaud: Metall. Mater. Trans. A, 1999, vol. 30, pp. 449-456

17. H. Sato, T. Kitagawa, K. Murakami, and T. Kawawa: Tetsu to Hagane, 1975, vol. 61, S471

18. K. Miyamura, A. Ochi, K. Kanamaru, and N. Kaneko: Tetsu to Hagane, 1976, vol. 62, S482

19. K. Marukawa, M. Kawasaki, T. Kimura, and S. Ishimura: Tetsu to Hagane, 1978, vol. 64 S661

20. K. Narita, T. Mori, K. Ayata, J. Miyazaki, and M. Fujimaki: Tetsu to Hagane, 1978, vol. 64, S152

21. Y. Sugitani, M. Nakamura, H. Kawashima, and M. Kawasaki: Tetsu to Hagane, 1980, vol. 66, $S 193$

22. M. Rappaz, A. Jacot, and W.J. Boettinger: Metall. Mater. Trans. A, 2003, vol. 34, pp. 467479

23. N. Wang, S. Mokadem, M. Rappaz, and W. Kurz: Acta Materialia, 2004, vol. 52, pp. 3173-3182

24. H. Fujii, T. Ohashi, and T. Hiromoto: Tetsu to Hagane, 1976, vol.62, S484

25. T. Matsumiya, M. Ito, H. Kajioka, S. Yamaguchi, and Y. Nakamura: ISIJ Int, 1986, vol. 26, pp. 540-546

26. Q. Chen and B. Sundman: Mater. Trans., 2002, vol. 43, pp. 551-559

27. M. Hillert: Phase Equilibria, Phase Diagrams and Phase Transformations, Cambridge University, 1998

28. T. Koshikawa, C.A. Gandin, M. Bellet, H. Yamamura, and M. Bobadilla: ISIJ Int, 2014, vol. 54, pp. 1274-1282 
29. T. Carozzani, C.A. Gandin, H. Digonnet, M. Bellet, K. Zaidat, and Y. Fautrelle: Metall. Mater. Trans. A, 2013, vol. 44, pp. 873-887

30. C.A. Gandin: Acta Mater., 2000, vol. 48, pp. 2483-2501

31. H. Fujii, T. Ohashi and T. Hiromoto: Tetsu to Hagane, 1976, vol.62 , pp. 1813-1822

32. M. Bellet and V.D. Fachinotti: Comput. Meth. Appl. Mech. Eng., 2004, vol. 193, pp. $4355-$ 4381

33. M. Bellet, O. Jaouen, and I. Poitrault: Int. J. Num. Meth. Heat Fluid Flow, 2005, vol. 15, pp. 120-142

34. B.G. Thomas and M. Bellet: Modeling of stress, distortions and hot tearing, In ASM

Handbook Volume 15: Casting, Division 4: Modeling and Analysis of Casting Processes, American Society of Metals, 2008, pp. 449-461

35. T. Koshikawa, M. Bellet, H. Yamamura, and M. Bobadilla: SteelSim2013, $5^{\text {th }}$ Int. Conf. on Modelling and Simulation of Metallurgical Processes in Steelmaking, Ostrava, Czech Republic, September 10-12, 2013, DVD published by the Czech metallurgical Society, 9 pages 36. Iron and Steel Institute of Japan: Mechanical behavior in Continuous Casting, ISIJ, 1985, NCID:BN03702225 (Citation Information by National institute of informatics: CiNii) 37. A. Palmaers, A. Etienne, and J. Mignon: Stahl und Eisen, 1979, vol. 99, pp. 1039-1050 38. P. Shi: TCS steels/Fe-alloys database V6.0 Thermo-Calc Software AB, Stockholm, Sweden, 2008

39. Thermo-Calc, TCCS manuals Thermo-Calc software AB, Stockholm, Sweden, 2013 40. British Iron and Steel Research Association: Physical constants of some commercial steels at elevated temperatures (based on measurements made at the National Physical Laboratory, Teddington), Butterworths Scientific Publications, 1953

41. G. Lesoult, C.A. Gandin, and N.T. Niane: Acta. Mater., 2003, vol. 51, pp. 5263-5283 42. V.D. Fachinotti, S. Le Corre, N. Triolet, M. Bobadilla, and M. Bellet: Int. J. Num. Meth. Eng., 2006, vol. 67, pp. 1341-1384

43. T. Koshikawa, M. Bellet, C.A. Gandin, H. Yamamura, and M. Bobadilla: Proc. MCWASP $X I V, 14^{\text {th }}$ Int. Conf. on Modeling of Casting, Welding and Advanced Solidification Processes, Awaji Island, Japan, 21-26 June 2015, H. Yasuda (ed.), IOP Conference Series: Materials Science and Engineering 84 012096, 8 pages 


\section{Tables}

Table 1. Compositions and experimental conditions.

\begin{tabular}{|c|c|c|c|c|c|c|c|c|c|c|}
\hline & \multicolumn{6}{|c|}{$\begin{array}{c}\text { Composition } \\
\text { (Mass Pct) }\end{array}$} & \multirow{2}{*}{$\begin{array}{c}\begin{array}{c}\text { Mold } \\
\text { removal }\end{array} \\
(\mathrm{s})\end{array}$} & \multirow{2}{*}{$\begin{array}{c}\begin{array}{c}\text { Punching } \\
\text { start }\end{array} \\
(\mathrm{s})\end{array}$} & \multirow{2}{*}{$\begin{array}{c}\begin{array}{c}\text { Displace- } \\
\text { ment }\end{array} \\
(\mathrm{mm})\end{array}$} & \multirow{2}{*}{$\frac{\text { Velocity }}{\left(\mathrm{mm} \mathrm{s}^{-1}\right)}$} \\
\hline & $\mathrm{C}$ & $\mathrm{Si}$ & $\mathrm{Mn}$ & $\mathrm{P}$ & S & $\mathrm{Al}$ & & & & \\
\hline$\underline{\text { Target }}$ & 0.21 & 0.24 & 1.64 & 0.032 & 0.007 & 0.090 & - & - & - & - \\
\hline $\mathrm{N}-2$ & 0.20 & 0.20 & 1.47 & 0.020 & 0.010 & 0.038 & 450 & 574 & 6 & 2.0 \\
\hline $\mathrm{N}-3$ & 0.19 & 0.24 & 1.50 & 0.022 & 0.010 & 0.064 & 457 & 517 & 6 & 1.0 \\
\hline N-4 & 0.19 & 0.21 & 1.49 & 0.021 & 0.010 & 0.064 & 300 & 499 & 6 & 0.5 \\
\hline N-5 & 0.19 & 0.21 & 1.50 & 0.020 & 0.010 & 0.041 & 321 & 510 & 6 & 0.25 \\
\hline N-6 & 0.20 & 0.21 & 1.48 & 0.021 & 0.010 & 0.055 & 340 & 510 & 3 & 0.25 \\
\hline
\end{tabular}

Table 2. Extent of the brittleness temperature range (BTR) calculated with (LR) the lever rule approximation, (PE+PA) the partial- plus para-equilibrium approximation and (EX) deduced from measurements. The corresponding solidification paths and exact alloy composition are reported in Figure 3.

\begin{tabular}{lccc} 
& LR & PE+PA & EX \\
\cline { 2 - 4 } BTR extent $(\mathrm{K})$ & 17.2 & 57.3 & 44.5
\end{tabular}




\section{Figures}
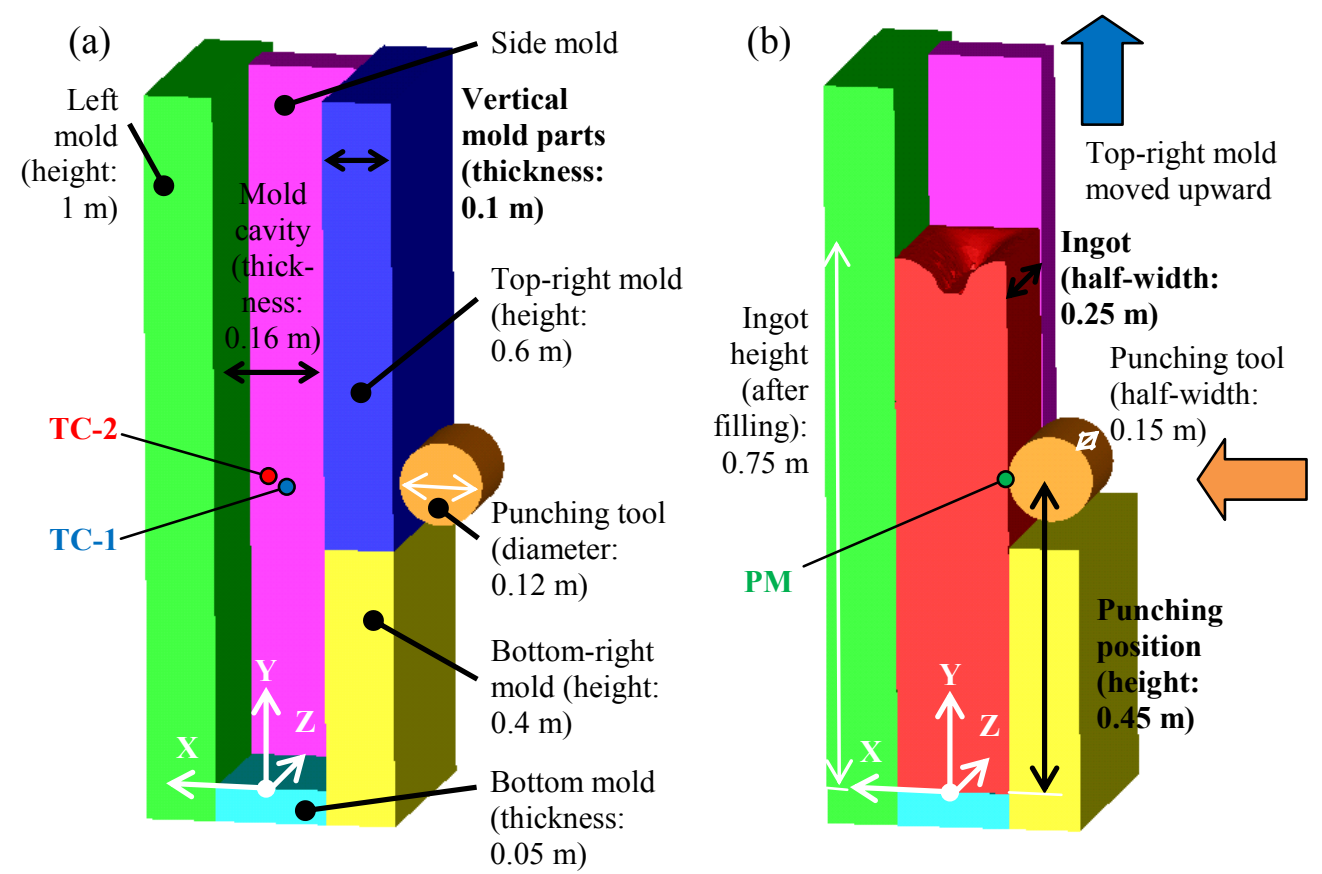

Figure 1. Schematic of half of the hot tearing experiment setup developed at Nippon Steel \& Sumitomo Metal Corporation showing configuration (a) prior to the filling stage and (b) at the onset of the punching stage when filling, partial solidification with the mold configuration shown in (a), removal of the top-right mold and displacement of the cylindrical punching tool to come into contact with the ingot. The coordinate system is defined in (a). The $\mathrm{Y}=0 \mathrm{~m}$ plane is defined by the top surface of the bottom mold part, also defining the lowest ingot surface in (b). The Y-axis, opposite to the gravity vector, is directed toward the top of the ingot at mid-width and mid-thickness. The $\mathrm{X}$-axis is directed toward the fixed left-mold surface. Thermocouples, TC-1 and TC-2 are located at $(\mathrm{X}, \mathrm{Y}, \mathrm{Z})$ positions $(0,0.43,0.06) \mathrm{m}$ and $(0.02,0.43,0.16) \mathrm{m}$, respectively. As schematized, pyrometer measurement $(\mathrm{PM})$ is performed around the punched surface of the ingot, before and after punching. 
(a)

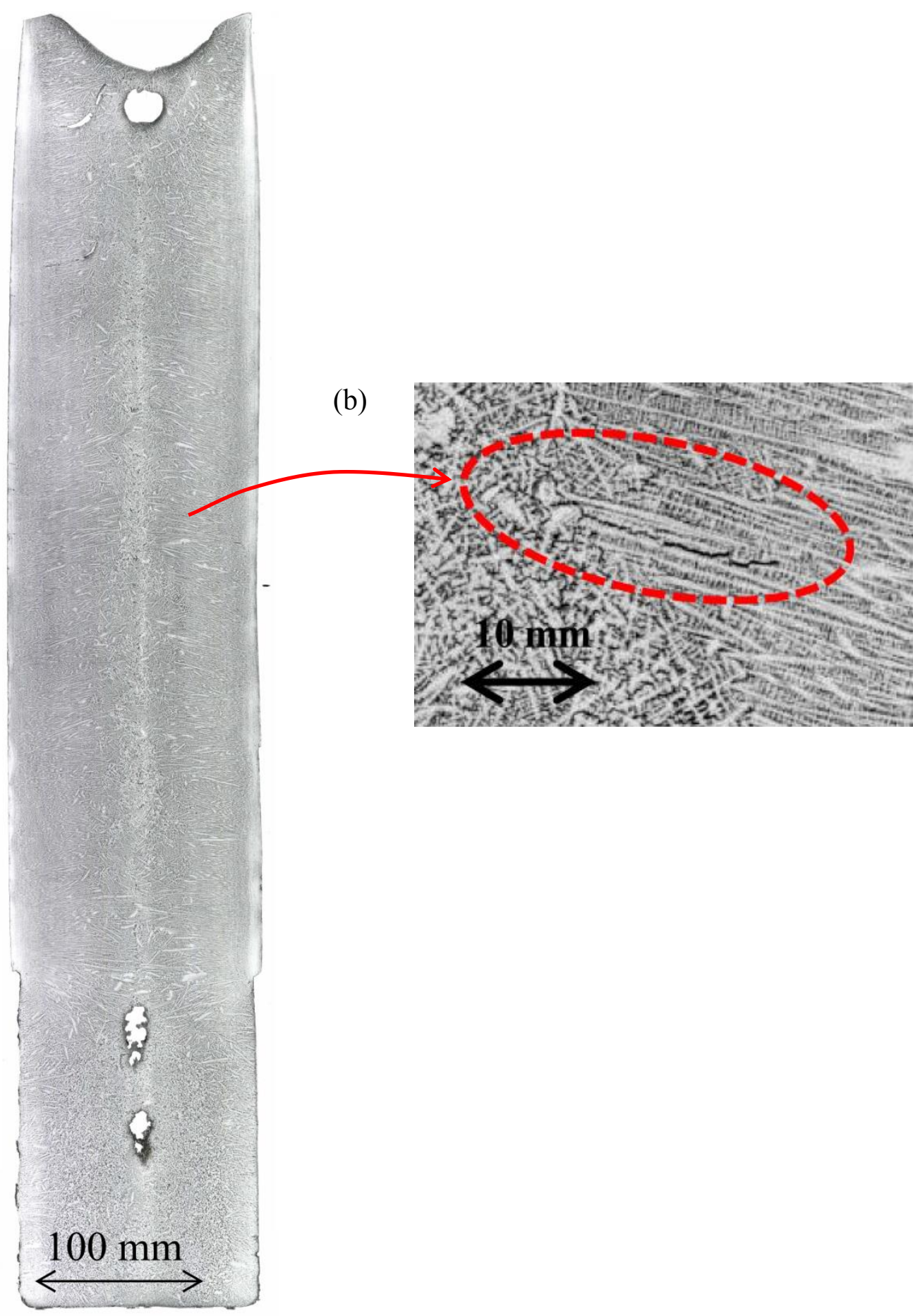

Figure 2. Micrographs for trial N-4 with (a) global view of the full ingot section in plane $\mathrm{Z}=0 \mathrm{~m}$ (Figure 1) and (b) magnified view in the rectangular red window shown in (a) revealing a hot tear circulated with a red dashed contour. Punching was performed from the right-hand-side surface of the ingot at the window height. 


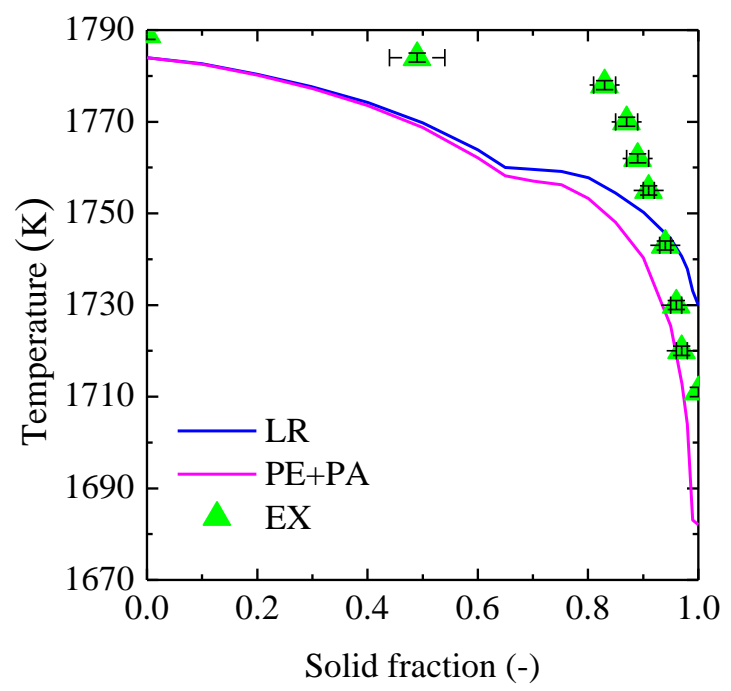

Figure 3. Three solidification paths for targeted alloy composition (Table 1) corresponding to (blue curve, LR) the lever rule approximation, (red curve, PE+PA) a combination of the partial- and para-equilibrium approximations [26, 27] and (green marks with error bars, EX) experimental investigation [28]. 
(a)



(b)

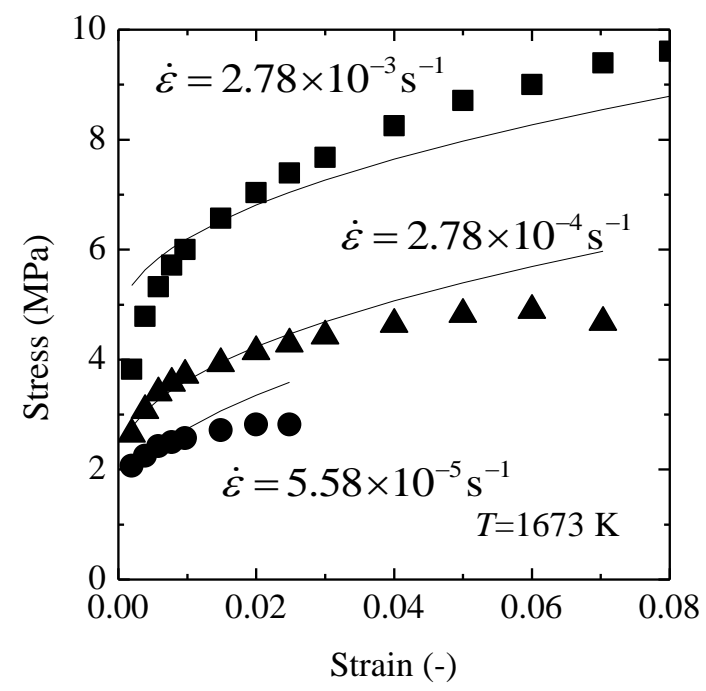

(c)

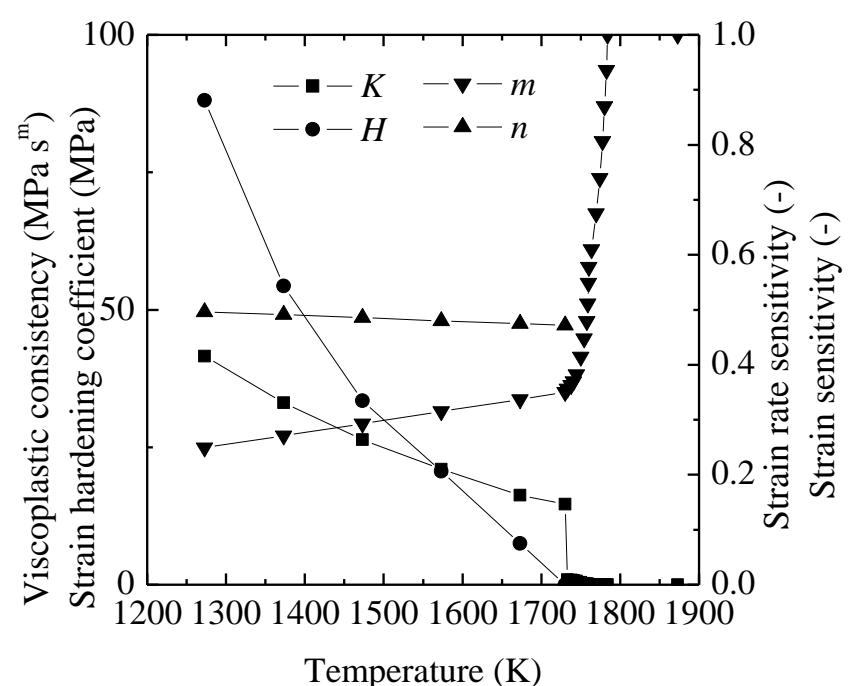

Figure 4. Strain-stress $(\bar{\varepsilon}-\bar{\sigma})$ curves established by means of (marks) high temperature tensile tests [36, 37] and (curves) calculations based on equation (12) for (a) 3 temperatures from $1273 \mathrm{~K}$ to $1573 \mathrm{~K}$ at constant strain rate, $6.67 \times 10^{-4} \mathrm{~s}^{-1}$, (b) at a higher temperature, $1673 \mathrm{~K}$, for 3 strain rates in range $5.58 \times 10^{-5} \mathrm{~s}^{-1}$ to $2.78 \times 10^{-3} \mathrm{~s}^{-1}$ and (c) obtained constitutive parameters as a function of temperature. 
(a)

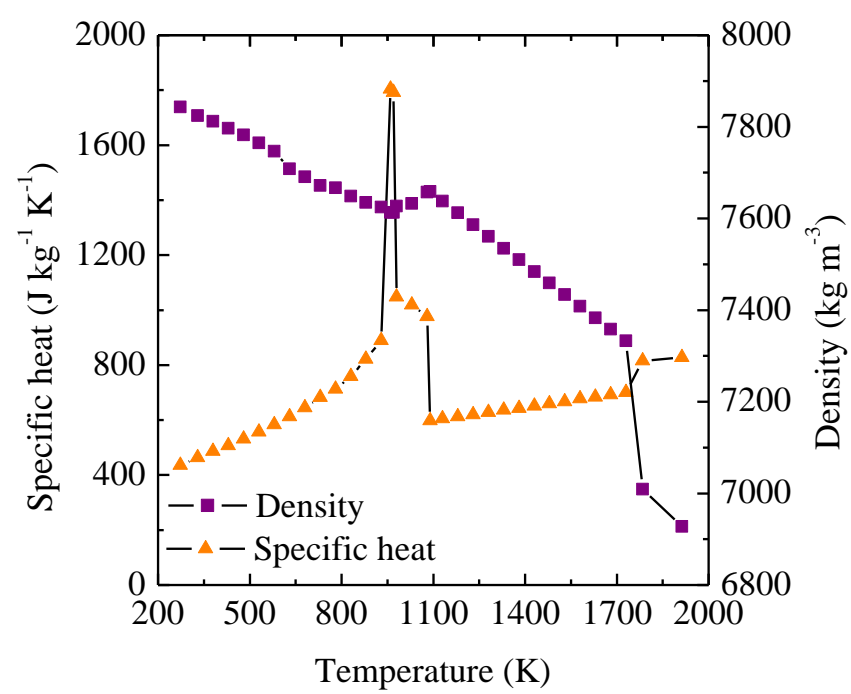

(b)



Figure 5. Temperature-dependent average properties for thermomechanical simulations including (a) specific heat per unit mass $c_{P}$ and density $\rho$ while assuming full equilibrium $[38,39]$ and (b) thermal conductivity $\lambda[40]$. 


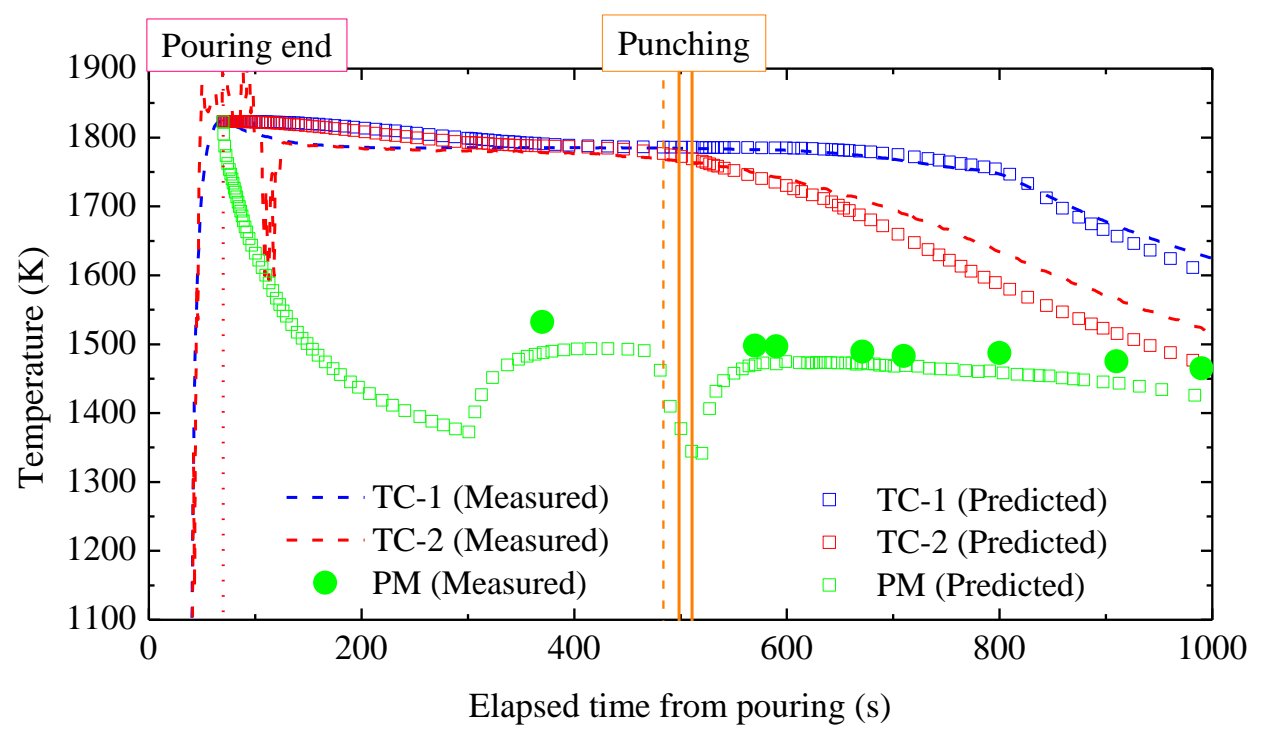

Figure 6. Cooling curves (dashed) measured during trial N-4 and (plain) computed. Positions of thermocouples TC-1 and TC-2 and pyrometer PM are reported in Figure 1. 
$(\mathrm{N}-4)$

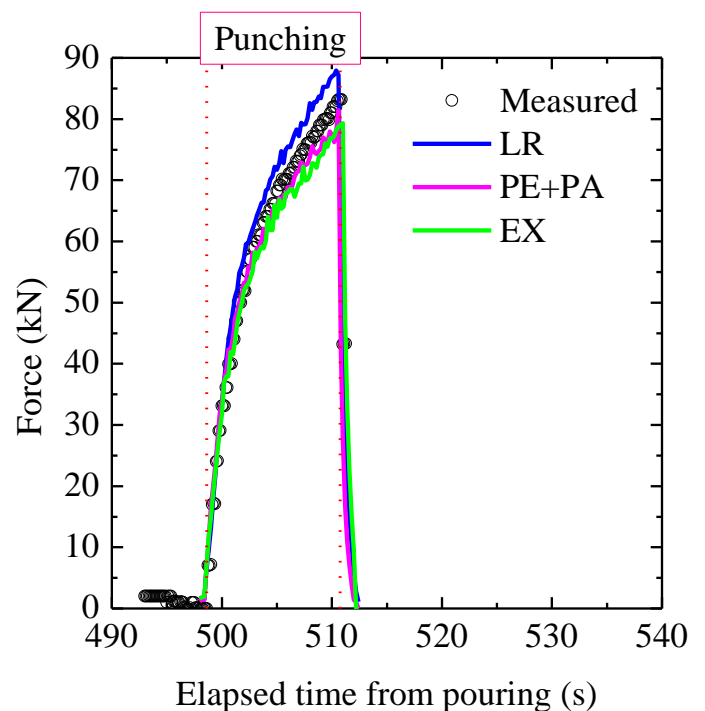

$(\mathrm{N}-5)$

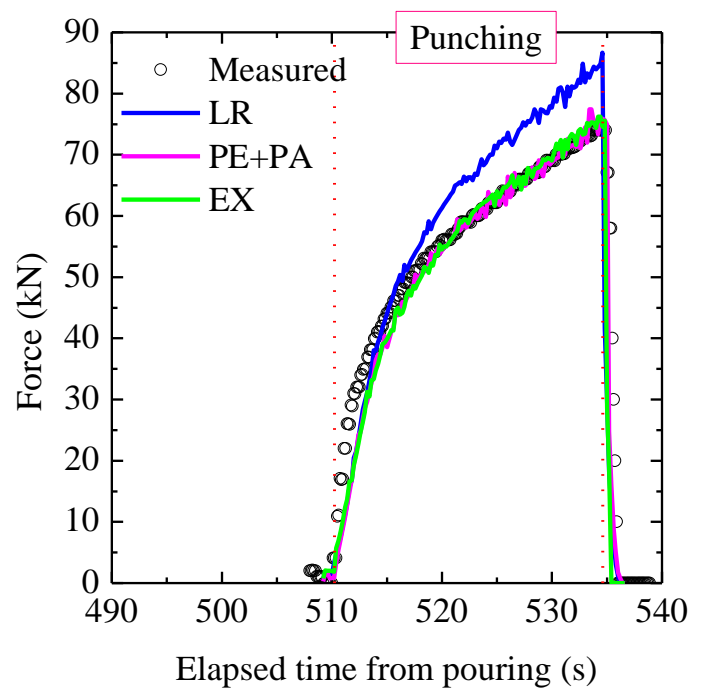

$(\mathrm{N}-6)$

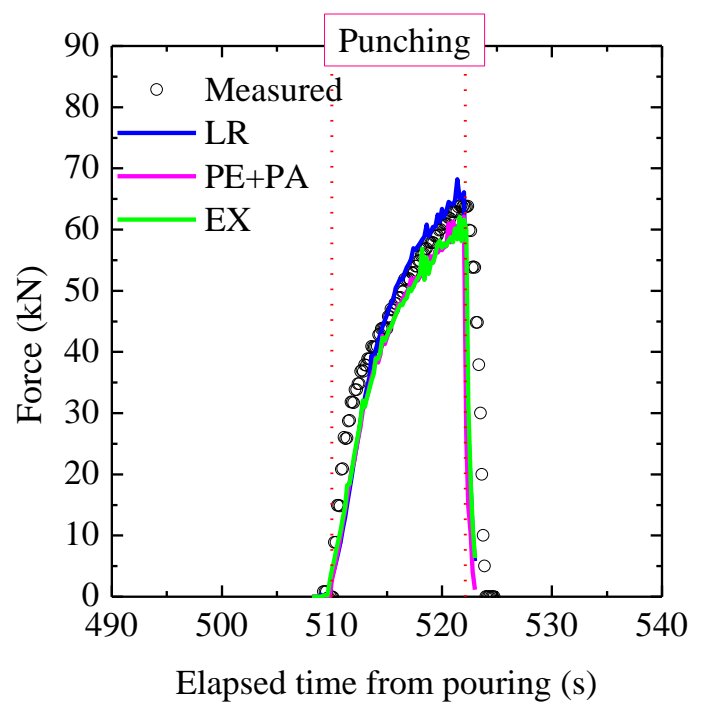

Figure 7. Time evolution of the reaction force due to the displacement of the punching tool during trial N-4, N-5 and N-6. Curves correspond to (black marks) measurements thanks to hydraulic system used to impose the movement of the cylindrical tool and (curves) simulations. Results are presented as a function of the 3 solidification paths presented in Figure 3. 


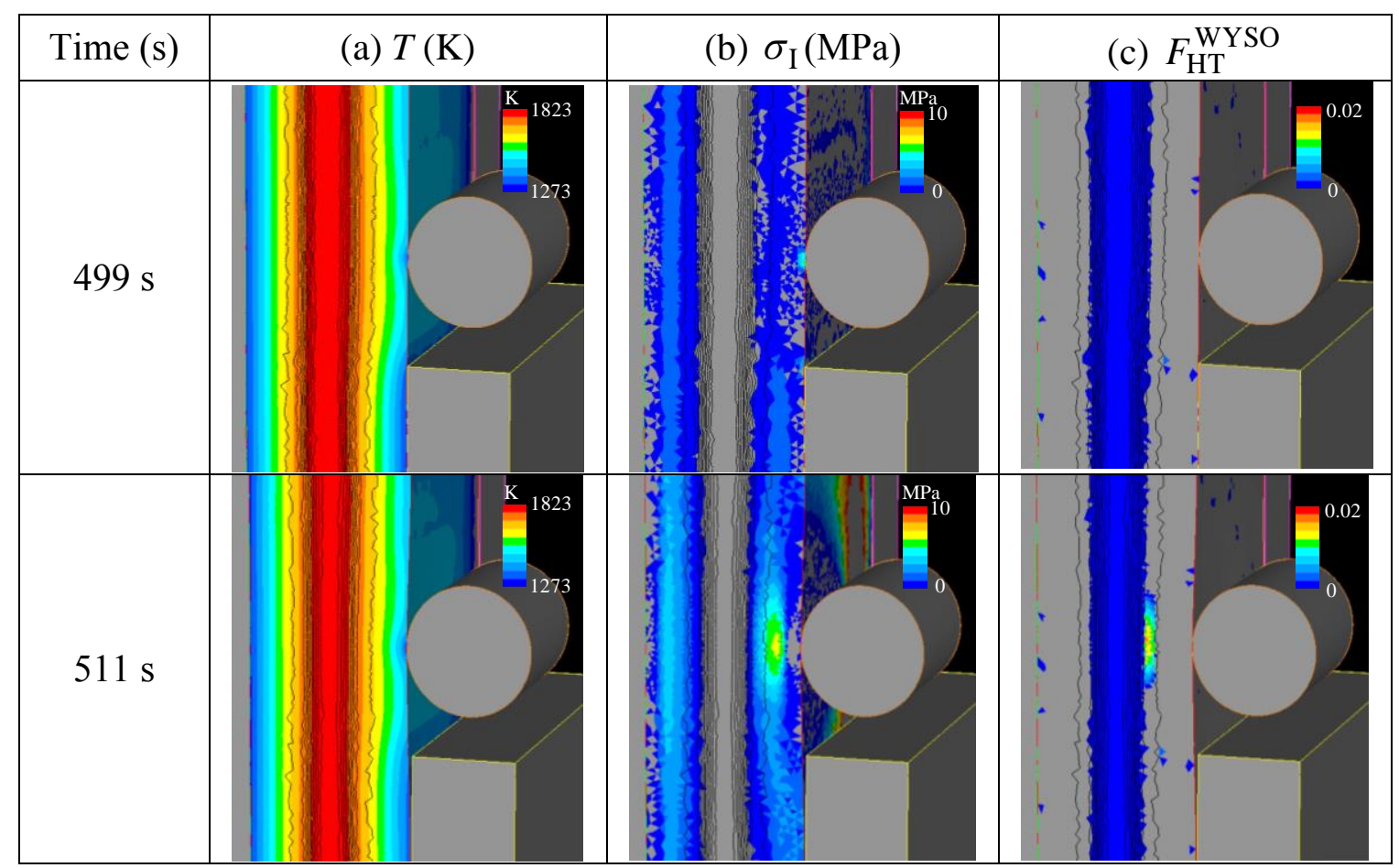

Figure 8. Predicted results for trial N-4 (Table 1) with the PE+PA solidification path (Figure 3, Table 2) showing (a) the temperature field, (b) the regions with positive values of the first principal stress, i.e. under tension, the gray regions within the ingot being under compression, and (c) the hot tearing criterion $F_{\mathrm{HT}}^{\mathrm{WYO}}$. The top and bottom lines show the different fields just before and after punching, respectively. Black vertical lines indicate iso-liquid fraction contours from 0 to 100 pct with 10 pct step. 


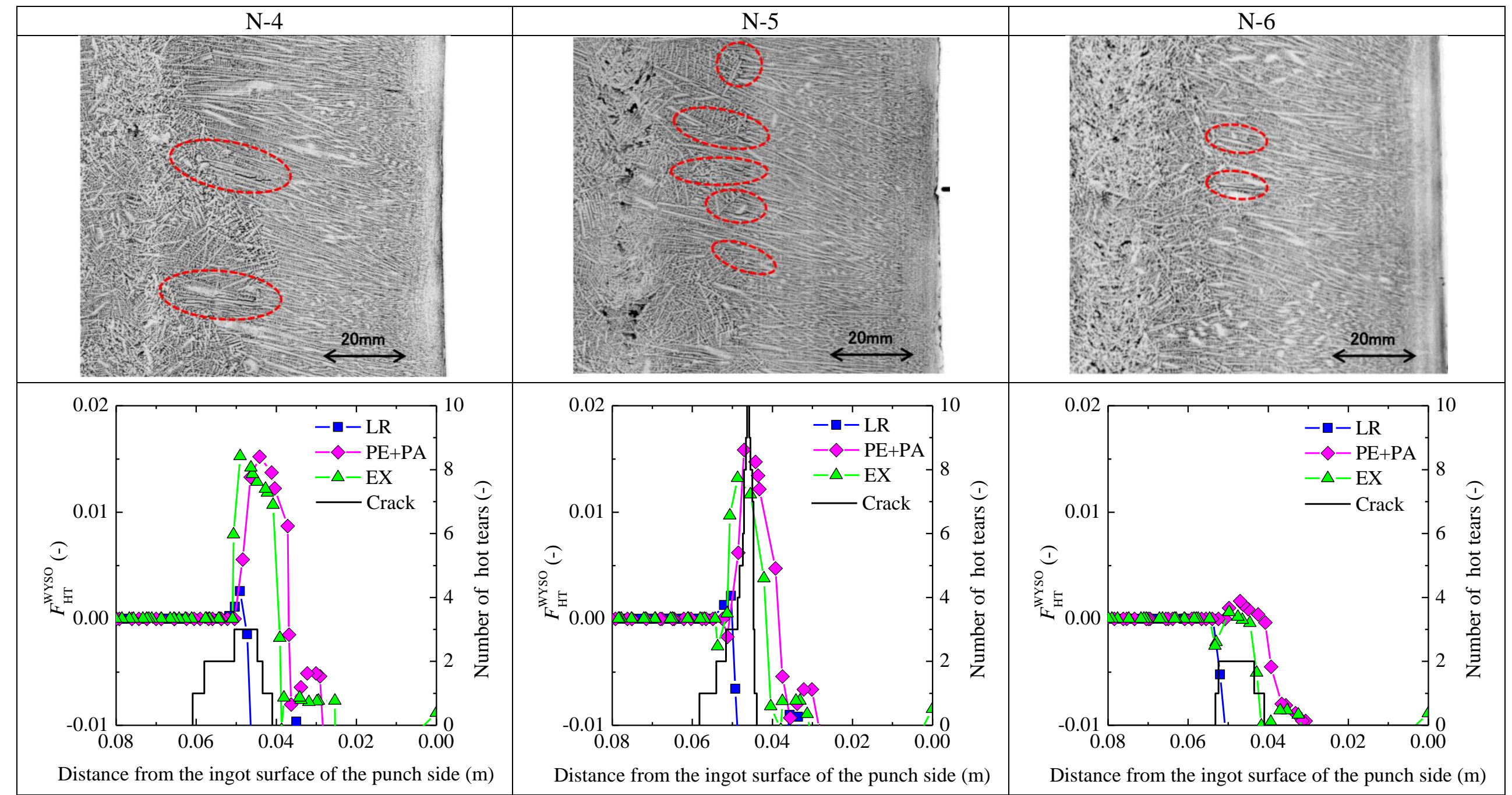

Figure 9. Magnified micrographs for trials N-4, N-5 and N-6 on the top. In all cases, hot tears are observed and circled with dashed red contours. Note that the top circle crack in N-4 is the same as the one shown in Figure 2(b). Also, the view being limited, not all cracks found are shown. Profiles along the ingot thickness for (black curve, right-hand-side legend) the number of hot tears and (colored curves, left-hand-side legend) the hot tearing criterion $F_{\mathrm{HT}}^{\mathrm{WYSO}}$ on the bottom. Results are presented as a function of the 3 solidification paths presented in Figure 3 for trials N-4, N-5 and N-6. 


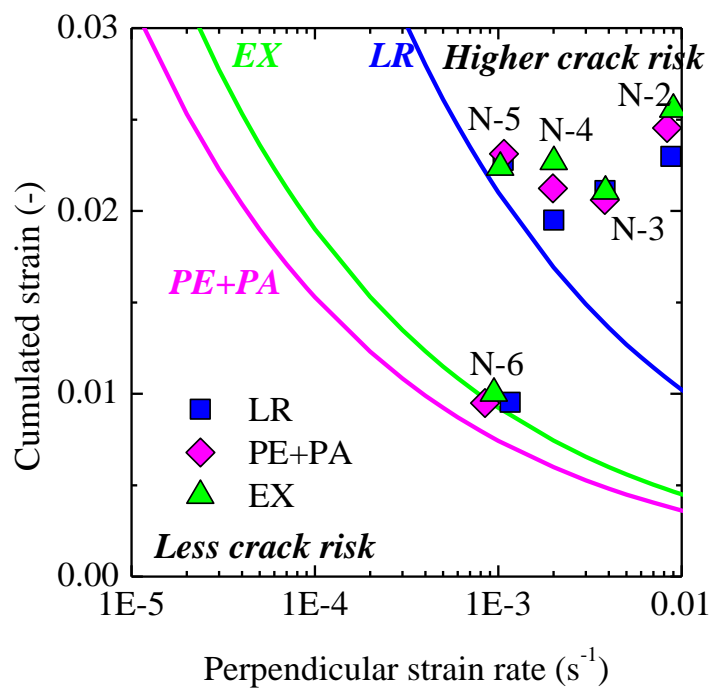

Figure 10. Computed cumulated strain $\int_{B T R} \dot{\hat{\varepsilon}} \mathrm{d} t$ as a function of the strain rate $\dot{\hat{\varepsilon}}$ perpendicular to the temperature gradient calculated when passing through the BTR. Values are taken from the $F_{\mathrm{HT}}^{\mathrm{WYSO}}$ profile at the punching height, an example being shown in Figure 9. The three continuous curves indicate the strain limit $\hat{\varepsilon}_{\mathrm{c}}$ (Eq. (13)). 


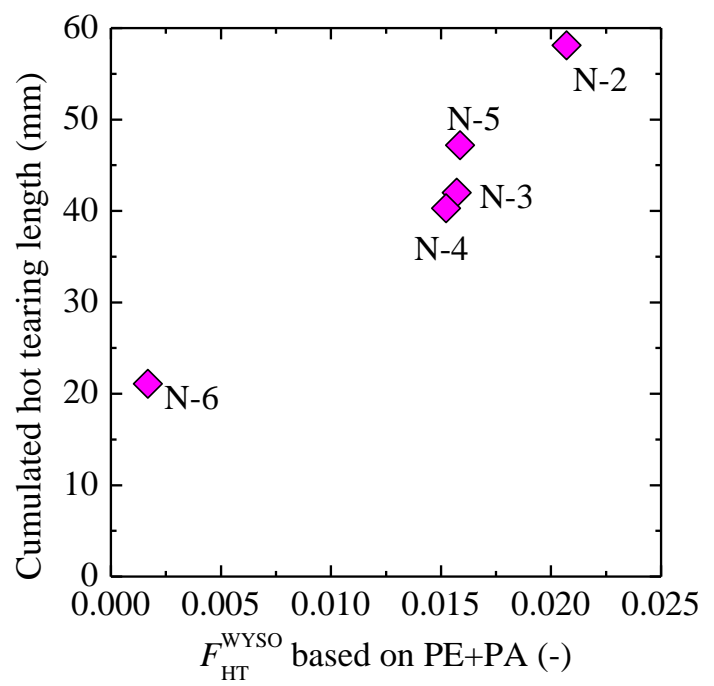

Figure 11. Cumulated hot tearing length measured as a function of the calculated value of the maximum hot tearing criterion $F_{\mathrm{HT}}^{\mathrm{WYSO}}$ using the $\mathrm{PE}+\mathrm{PA}$ solidification path. 